\title{
LENGUAJE Y CULTURA: UNA MIRADA SEMIÓTICA AL DISCURSO DEL ARRABAL
}

\author{
LANGUAGE AND CULTURE: A SEMIOTIC LOOK \\ AT DISCOURSE FROM THE ARRABAL
}

\section{ALEJANDRA LEAL LADRÓN DE GUEVARA*}

\section{RESUMEN}

Este estudio describe el lenguaje semiótico del tango de principios del siglo XX como un macrodiscurso del arrabal mediado por el comportamiento lingüístico y cultural de los agentes que comparten en el barrio, espacio de la subcultura bonaerense. Por cuanto es en el suburbio donde se originan los códigos agenciales, sonido, espacio y cromático de esta cultura del arrabal, asimismo, en la enciclopedia del hombre común se imparte el mensaje del tango, se entrelaza y se desarrolla un nuevo código de relaciones para la vida: el malevaje. Para observar esto se analizará el sistema que participa en la semiosis a partir del texto discurso "Melodía de arrabal" (1932) correspondiente al corpus de 30 canciones (Arteche, 1985; Gobello, 1997), en las cuales se diferenciarán los distintos niveles del discurso desde un plano superficial hasta el subyacente. Por un lado, el nivel sintáctico y semántico de los signos y, por otro, sus interpretaciones en el nivel pragmático reflejadas en las inferencias: como las implicaciones de la formación, desarrollo histórico y sociocultural del tango canción.

Palabras clave: Semiótica, código, tango, arrabal.

\section{ABSTRACT}

This study describes the semiotic language of the tango at the beginning of the 20th century as a macro discourse of the suburb that is mediated by the linguistic and cultural behavior of the agents who share in the life of the barrio, the space of Buenos Aires subculture. Since it is in the suburbs where the agential codes originate, sound,

* Doctora en Ciencias Humanas, Lingüística y Literatura, Universidad Austral de Chile Sede Puerto Montt. Puerto Montt, Chile. E-mail: alejandraleal@spm.uach.cl 
space and chromatics of this arrabal, so it is that from the encyclopedia of the common man the message of the tango is imparted, becomes entangled with and leads to the development of a new codes of relations for life: malevaje. This paper will analyze the system involved in the semiosis of the textual discourse of "Melodía de Arrabal" (1932), corresponding to a body of 30 songs (Arteche, 1985; Gobello, 1997), in which levels of discourse will be differentiated, from a superficial plane to an underlying one. On the one hand, the syntactic and semantic level of the signs and on the other, their interpretations on a pragmatic level that are reflected in inferences: such as the implications of the formation, historical and sociocultural development of the tango as song.

Key words: Semiotics, codes, tango, arrabal.

Recibido: 07.07.11. Aceptado: 12.08.11.

\section{INTRODUCCIÓN}

PARTIR DE LOS ANTECEDENTES socioculturales de la historia del tango,
el barrio se conforma como el espacio para la temática del tango
canción. Aunque tanto el uno como el otro forman parte de un espacio geográfico, aquel se opone a la ciudad como el centro a la periferia. Esta oposición se expresa por motivaciones de controversia social, en la medida que en un extremo el barrio está asociado a un mundo de amparo, hermosura y bondad y la ciudad se visualiza con rasgos negativos producto del rechazo ejercido contra la clase baja y la excesiva competitividad del medio. Esto es decir que, establecer el concepto del tango como lenguaje de la barriada, equivale a enunciar un concepto en cuya abstracción se define un objeto genérico de una especial manera de lenguaje conformado técnicamente mediante la cultura urbana predominante (Poblete, 1985). El tango, cuyos orígenes se encuentran aproximadamente a partir de 1880 en América, es un fenómeno sociocultural; es un producto musical que resultó de una mezcla entre el candombe de los negros, la habanera, la danza española andaluza y, por supuesto, la milonga. Aunque para algunos sea un baile vulgar, una importante mayoría lo considera la música del arrabal y, si su lenguaje es un elemento que violenta la pureza de la lengua, hoy está reconocido y parece ser un orgullo su "cuna ranera" (Serna, 1979; Arteche, 1985; Poblete, 1985; Gobello, 1997a; Espíndola, 2002). No obstante, para explicar el sentido del tango es necesario eliminar todos estos estereotipos, porque este es un elemento propio de la lengua en donde la sociedad cumple el rol permanente de valorarla para ajustar o modificar su sentido (Valdivieso, 1983; Salamanca, 2010), el que participa de toda una gama de factores sociológicos presentes en la vida, como literarios y musicales que 
lo integran para configurar una realidad que tiene validez artística y, sobre todo, representativo de un conflicto vital y de unas relaciones que perviven, así se vayan transformando las condiciones sociales en las cuales tuvo su origen (Poblete, 1985).

El contexto donde circula la temática del tango se encuentra vinculado al espacio del suburbio bonaerense en oposición a la vida de la ciudad. Por esto, los elementos que han producido la cultura de la orilla se complementan con el lunfardo "jerga de ladrones y gente del bajo fondo porteño que se extendió a la población orillera" (Espíndola, 2002) y que, estructuralmente, en nada se diferencia de la coa chilena o de la giria brasileña (Serna 1979). En suma, el lunfardo será el elemento lingüístico y de interacción comunicativa usado por los lunfas en el marco del "submundo", el suburbio; en donde prevalece el estereotipo del tanguero: "Mezcla de gaucho y malo, y de delincuente siciliano, viene a ser el arquetipo envidiable de la nueva sociedad: es rencoroso y corajudo, jactancioso y macho" (Sábato, 1985).

Resumiendo lo anterior, la categoría lingüística a la cual se acoge el tango canción de los orígenes corresponde a la clase baja y, según apreciaciones academicistas del lenguaje, es vulgar y grosero para la época. Además, tango y lunfardo recorren un proceso evolutivo paralelo: el tango se inicia como música de quilombo "burdel" o "casa pública en donde se ejerce la prostitución” (Espíndola, 2002); el lunfardo, como el lenguaje-jerga de ladrones y de gente vinculada al delito (Serna, 1979; Gobello, 1996, 1997b; Espíndola, 2002). No obstante, esta transformación fue parte de un proceso gestado históricamente a través de hechos que hicieron cambiar el panorama de Buenos Aires hacia fines del siglo diecinueve. Pues, la construcción del Puerto Nuevo, el fin de la guerra con Paraguay y, consecuentemente, la federalización de Buenos Aires, obligó al desplazamiento de la población hacia la orilla del Río de la Plata, donde se vieron hombres solos, haciendo más profundo el abismo entre la clase alta y la baja. En este contexto nace el arrabal en barrios como La Boca (hoy sustento del turismo porteño), los Corrales Viejos, Miserere y Bajo Belgrano, contrastando con los exclusivos del centro bonaerense. Esto último, junto a la inmigración tendría la secuela de la indigencia y la miseria (Serna 1979; Espíndola, 2002). A ciencia cierta, el tango canción es un fenómeno que participa de factores sociales, literarios y lingüísticos. De este último, el lunfardo vinculado a los actuales argentinismos, ya ha pasado sus fronteras, integrándose en algo más que una realidad artística en países como Colombia o Chile (Salamanca, 2010). Por esto mismo, conforme a los diversos códigos que lo controlan como "lenguaje de la barriada" se ajusta a parámetros que se significan sólo en interposición a sistemas paralelos e interpuestos como subcódigos. En 
suma, será a través de estos que se significa y define una visión particular del mundo; la representación de un conflicto vital que, hasta hoy, conforma unas relaciones que perviven más allá de la letra haciendo historia y cultura (Eco, 1992, 1995).

\section{MARCO REFERENCIAL}

La semiótica, del griego "semeion", refiere al signo como la "ciencia que estudia la vida de los signos en el seno de la vida social" (Saussure, 1916) $y$, en tanto que es ciencia, guarda el propósito de "reconstruir el funcionamiento de sistemas de signos" (Barthes et al., 1970). Aunque el "único problema que un signo suscita para ser reconocido es el de su existencia" es necesario identificar las unidades o "marcas distintivas" con criterios de "distintividad" (Benveniste, 1997). Retomando estas ideas previas, este estudio semiótico consiste en identificar las unidades, describir las marcas distintivas y descubrir los criterios de identidad de los signos en el sistema de la lengua para encontrar, por un lado, el punto de correlación entre la expresión y el contenido y, por otro, los valores que emanan de un sistema identificable en sus unidades culturales proporcionadas por el código; pues, en este plano se entenderán las unidades y las reglas combinatorias como el léxico y la sintaxis (Eco, 1995). Sin embargo, la función semiótica en sí misma y como unidad combinable no supone una dicotomía en el código; en este sentido, este último proporciona una descripción limitada de la función semiótica, la que abarca puntos nodales en que la función puede amalgamarse con otras. De manera que la función semiótica con su superelevación de connotaciones es regulada por un código o supra código donde se introducen los propios nudos combinatorios (Eco, 1995). En la práctica de este análisis, el sistema social de la lengua contiene un macrosistema de códigos interconectados: a juicio de este modelo se encuentra el código agencial: de género (masculino y femenino, con diferenciación etaria en el segundo), de sonido (armónico e inarmónico), cromático (luz y sombra) y de espacio (abierto y cerrado). Estos, en el juego de la interacción, conducen a identificar el macrocódigo del arrabal donde habita el malevaje. Pues, es en este último donde se abordan los problemas pragmáticos, ya que el código mueve al destinatario mediante funciones imperativas y emotivas ligadas a las connotaciones verbales (Eco, 1995). En este sentido y con el propósito de hacer la lectura de los signos implicados en la semiótica del tango canción y el discurso del arrabal, se hace referencia a los niveles del discurso, esto es, cada uno de los estratos en que se puede leer un texto 
y, por supuesto, el reticulado de signos que refuerza la propuesta sígnica en los diferentes textos (Anexos 1 y 2). Sin desapreciar que el sujeto de la enunciación es el autor textual del suburbio y quien simpatiza o pertenece al suburbio como, además, el destinatario textual del tango canción (Eco, 1995). Este hombre del barrio es el mismo que participa y vive los códigos del arrabal y, por consiguiente, es quien los interpreta para sí en su contexto cultural y en correspondencia al momento histórico conformado a inicios del siglo XX; en suma, en el apogeo de la vida y la música del tango. En la medida que los códigos son una abstracción e interpretación de cómo opera en este espacio la unidad cultural del arrabal, la lectura de los niveles del lenguaje semiótico implican la dimensión sintáctica para designar la denotación del significado semántico y propiamente denotativo, sobre el cual se realiza la interpretación e inferencias pragmáticas (Morris, 1985; Roa, 1989; Reyes, 1997). Por esto mismo, en este estudio se toma distancia interpretativa para solo aislar los códigos indicados en la interacción de sus funtivos y, finalmente, ligarlos al macrocampo del arrabal. En resumen, en este análisis se significará el fenómeno sociolingüístico del lunfardo y se construirán los campos semánticos de los códigos: agencial, cromático, sonido y espacial de los textos del corpus, obteniéndose la representación final en la coherencia del discurso subyacente, esto es decir, el código del arrabal potenciado por el malevaje.

\section{ANÁLISIS EN LOS NIVELES TEXTUALES}

Para ilustrar el nivel sintáctico se ejemplifica con una estrofa de "Melodía de arrabal" (Le Pera y Battistella, 1932), cuya composición métrica es de consonancia como suele ser en la mayoría de los textos, destacándose las estrofas de números variables: "Barrio plateado por la luna, / rumores de milonga / es toda tu fortuna; / hay un fuelle que rezonga / en la cortada mistonga, / mientras que una pebeta, / linda como una flor, / espera, coqueta, / bajo la quieta luz de un farol". La conformación de las estrofas comprende nueve versos con rima consonante en cada uno de ellos, distribuidos de la siguiente manera: a, b, a, b, b, c, d, c, d.

En la construcción de la lectura interpretativa de los códigos se clasifican los sememas. Esto último, en la medida que un mismo significante denota y connota varias unidades semánticas del corpus como unidades previstas de significado cultural. De esta forma, el significado aludido se incorpora en campos semánticos con rasgos distintivos cuya pertinencia conforma cada uno de los códigos (agenciales, de sonido, de espacio y cromáti- 
co), los que justifican las interpretaciones y bases de la coherencia global de la propuesta sígnica (Eco, 1995). El campo semántico del código agencial se dispone en la presencia de agentes femeninos tanto de jóvenes como de adultas y, de masculinos, sin diferenciación etaria (ver Figuras 1 y 2); el código cromático, en signos de luz y de sombra; el de sonido, en armónicos e inarmónicos y; el espacial, en signos de exterior y de interior. A partir de estas figuras, el análisis de los signos de cada campo es registrado en el nivel sintáctico y el plano denotativo donde se produce la relación entre ellos, puesto que pululan en el barrio una serie de personajes cuya función social está determinada por los distintos roles que cada uno ejerce según la edad y la condición de arraigo al sistema en absoluta dependencia con el espacio físico. Así, los lexemas: conventillo, keko, cotorro, bulín, milonga, arrabal, San Juan, Pompeya, ranchitos, barrial, corralón y callejón, forman parte del código espacial (Figura 3), cuya estructura sintáctica expresa la significación denotativa del referente: barrio. Esta es la entidad abstracta que representa una convención y entidad cultural geográfica, vinculada a la acción de estos agentes comprometidos con las acciones propias y comunes de esta barriada. Se puede adelantar que estas expresiones son compartidas y valoradas en la periferia en oposición a aquéllas vinculadas al centro de la ciudad bonaerense donde preexiste la persecución de los agentes del malevaje.

Siguiendo con esta lectura de los campos semánticos leídos en el corpus, se registra la relación sintáctica del código agencial conformado por los personajes del espacio geográfico del barrio (Figuras 1 y 2). De manera que los lexemas femeninos entre jóvenes y adultas son: pebetas, paicas, minas, yiras, bacanas, grelas, viejas paicas, viejas madres y, entre los masculinos: los bacanes, caneros, canfinfleros, cirujas, compadres, compadritos, chorros, caferatas, mishés, los cuales tienen el referente en su mismo código remitido al uso del lunfardo, propio del lenguaje de los delincuentes rioplatenses y estereotipos sociales que cumplen un rol en el barrio y de quienes se infiere sean agentes del delito. De acuerdo a esto, cabe señalar que ellos se encuentran fuera del orden y la ley, realzando la vida grupal de la subcultura del arrabal.

Así, en el correlato de los signos del código del sonido (Figura 4) se identifica la lectura del discurso superficial cuyos funtivos del plano de la expresión se representan en los lexemas: gorjeo, ritmo, canción, cantares, canyengue, serenata, valsecito, melodía, son, queja; como también: rumores, llorando, rezonga, silbidos, los cuales se apoyan en el plano del contenido y cuyo significado es el referente sígnico del mismo código de entidades abstractas que conducen a la clasificación final de sonidos armónicos e inarmónicos.

A su vez, en la dimensión del nivel sintáctico, la relación entre signos del 
código cromático se presenta con variadas expresiones de luz y de sombra, prevaleciendo los lexemas como: luna, farol, estrellas y noche que, por cuanto tal, remiten en su estructura sintáctica a la significación denotada de los astros apreciados solo en la noche despejada (Figura 5).

\subsection{Nivel superficial: sintáctico y semántico}

En las siguientes figuras del nivel superficial se enumeran los componentes de los códigos: agenciales, espacial, sonido y cromático, conformados por los estereotipos sintácticos y su correspondencia semántica:

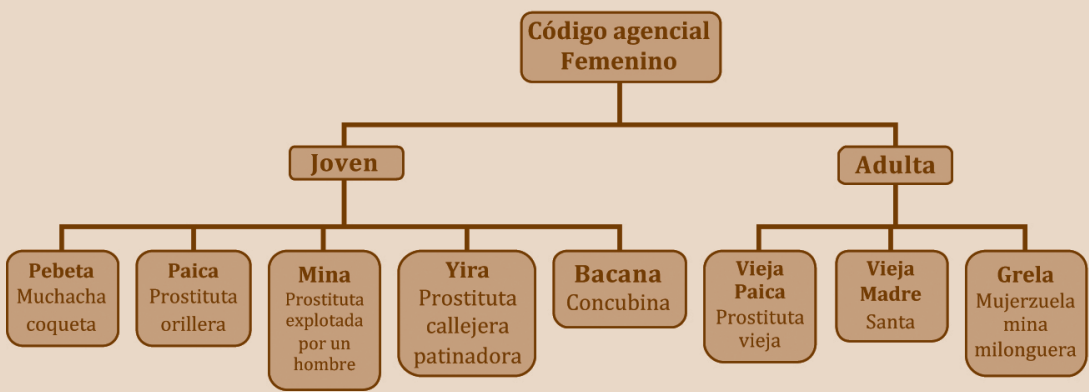

Figura 1.

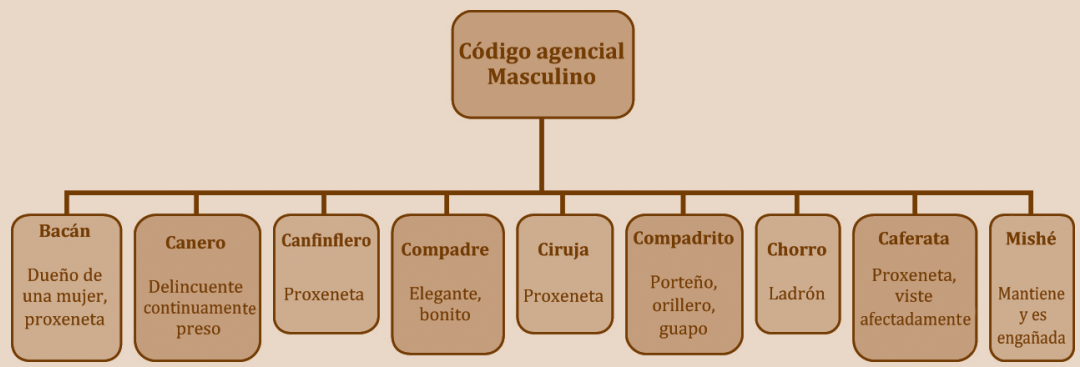

Figura 2.

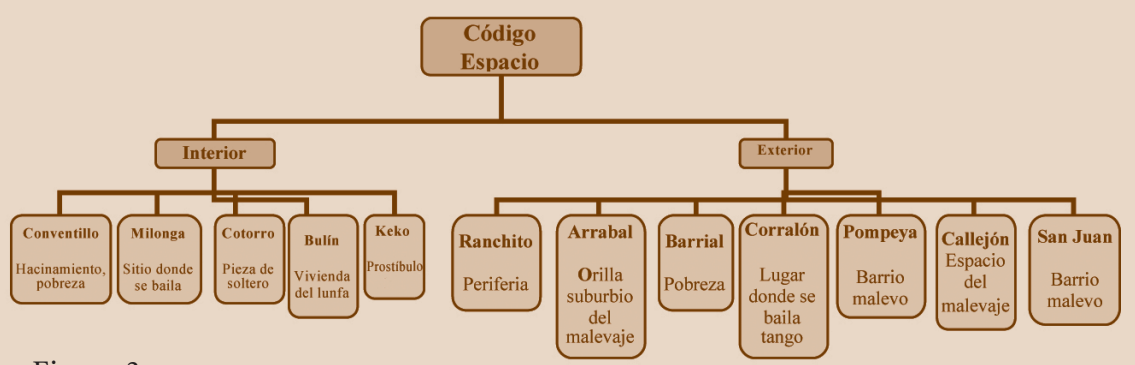

Figura 3. 


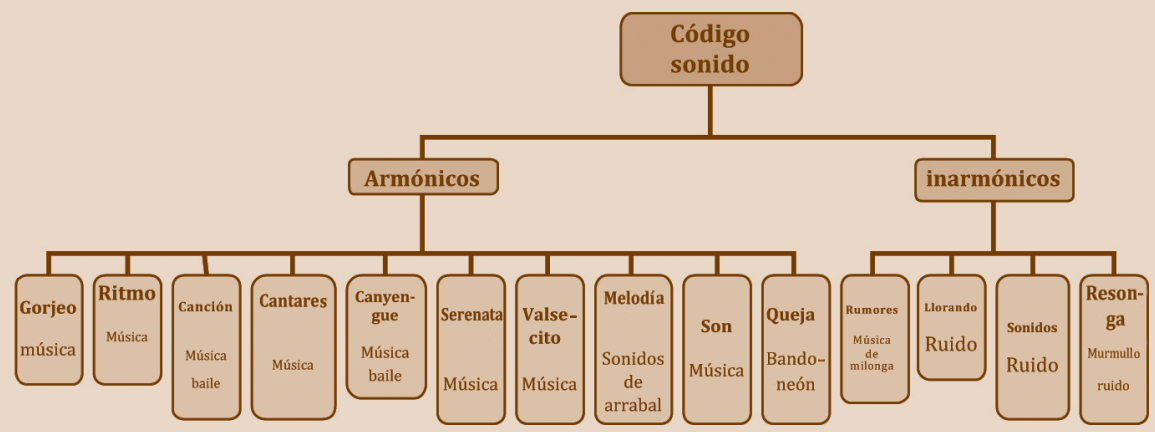

Figura 4.

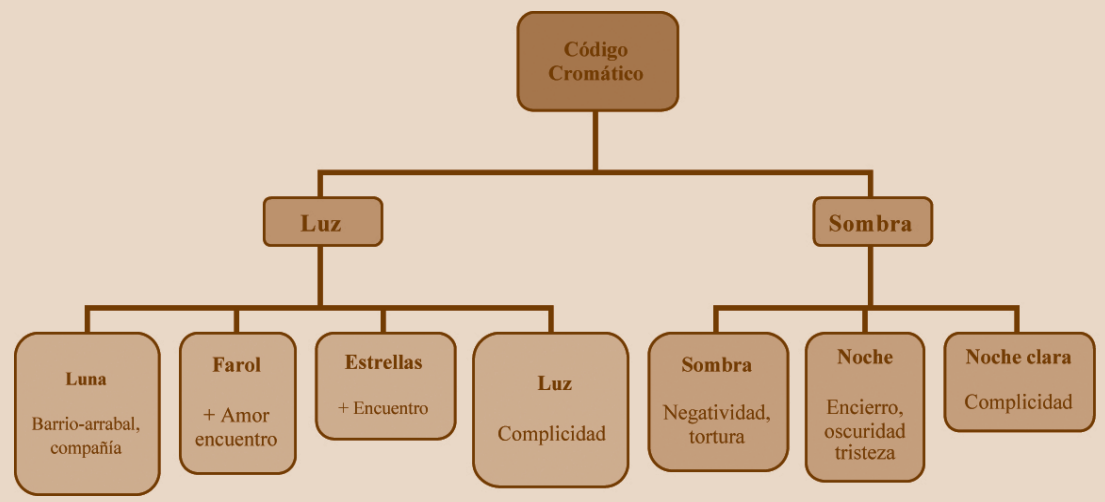

Figura 5.

\subsection{Nivel subyacente e interpretación}

Como se ha señalado, desde el plano superficial existe desplazamiento al plano subyacente en donde se relaciona un nuevo contenido para la misma expresión. Pues, a partir del precedente se reconoce el código connotativo, ya que los campos semánticos dan el sentido interpretativo de los signos. Estos se encuentran en relación dialógica creando las conexiones para la correspondiente interpretación. El despliegue de los campos semánticos formula los antecedentes de los signos del barrio otorgando otra significación o valor connotativo; en este último es donde se relacionan los sememas desde cuyos rasgos distintivos se leen los signos que configuran el arrabal (Eco, 1995). Por consiguiente, se dirá que en el plano subyacente coexisten la variedad de códigos ya enunciados en la lectura interpretativa. 
Desde el código agencial (Figura 1) los hombres comparten los semas de la transgresión a la norma como a la ley en las figuras del delincuente, el vagabundo, el ladrón, el cafiche y, entre las mujeres, el de la prostitución o la explotación sexual. En este último, el enunciado femenino pebeta tiene como referente lingüístico a una muchacha joven (Espíndola, 2002) que, a través del registro de las connotaciones, se correlaciona a otros signos que dialogan con éste. Pues, la pebeta "Linda como una flor", se presume en los llamados años de la flor de la vida donde la juventud se vincula con un nuevo contenido enlazado a otros signos del código del espacio, tales como: la noche, la coquetería, la luz de un farol en un barrio como el Pompeya o el San Juan. De esto último se infiere que ha de ser al amparo de la vida nocturna cuando ocurre la iniciación sexual de la muchacha, reforzando con su presencia de "Espera, coqueta" las condiciones propicias de la armonía para su ingreso al arrabal. Debe destacarse que mientras la luna es cómplice del sino del malevaje, siempre ilumina los espacios de la orilla con destellos de plata para seguirla y verla completar esta parte de su ciclo. En este sentido, se infiere que esta pebeta da sus primeros pasos con la perspectiva de conseguir en un futuro próximo las ventajas propias del estatus que establece la pertenencia al malevaje: la "mina" tanguera y "reina del festín", no obstante, cambia su aspecto y al final del ciclo "por muy poco" o "en la primera cita" por comida entregará su amor. Así, pues, el destino se cumple y de "linda como una flor" se trastoca en "flor de fango"; el nuevo nombre asignado a esta mujer que ha desflorado en la orilla ahora convertida en "paica arrabalera".

A través de las reglas semánticas se infiere que en el texto "Melodía de arrabal" existe una estrecha relación dialógica con otros textos como "Sur" o "Luna de arrabal". De modo que el protagonismo escénico del espacio de la subcultura del arrabal cobra vida al amparo de la oscuridad donde la luz no está semantizada en sí misma, puesto que ésta se relaciona en el rango propio que adquiere la complicidad de la luna: "las lunas suburbanas", "noche clara", etc. y la música a la cual también se acerca la luna, porque "quiere oír la serenata pintoresca del arrabal". Por lo mismo, este elemento tan referido en la literatura trágica de García Lorca, en estos textos canciones, adquiere vida pensante y se acerca, protagónica, como un murmullo en el aire camuflándose en un brebaje embriagador.

En el mismo escenario, los bohemios se transforman en agentes que se mueven y viven su sino en un espacio que es común en la periferia orillera del Río de la Plata. Estos son los espacios que connotan hacinamiento, vida nocturna y, por sobre todo, donde se comparten el signo del malevaje. Sue- 
len ser los barrios suburbanos como el San Juan o Pompeya que al amparo ribereño, junto a la sombra de la luz de la luna o los faroles, las estrellas instan el momento en que se genera la complicidad y la vida de estos seres nocturnos como el chorro, el bacán o el compadrito; pues estos agentes otorgan un nuevo significado a la presencia del porteño y orillero guapo con la armonía de la música. De manera que en consonancia al tránsito por los callejones "empedraos" y en dirección al keko, se intuye el ritmo del canyengue junto al tango y otros cantares propios de la vida nocturna que parecen ser las figuras obligadas y plenas de la melodía que armonizan el arrabal.

En este sentido y en absoluta oposición a los agentes de la ciudad, la música del tango es notoriamente de machos (López, 1998). Pues, ampliando lo señalado por Gobello (1996), el "amante" o "querido" es una de las voces que ejerce su poder sobre las hembras, sean pebetas, paicas o minas. Por esto se dirá que los agentes masculinos no tienen referente etario, ya que se nace y se muere macho emulando el escenario del tango canción. Sin embargo, este macho experimenta cambios psicológicos en la medida que es "amurado" o abandonado, lo cual no es privativo de su primera condición: herido, pero macho.

El medio propicio para actuar de estos machos surge en las noches claras, del mismo modo que acontece con el código cromático donde la mujer sólo entra al juego como aquella que vive al amparo del hombre, ya sea como prostituta o bacana, paica o yira, compartiendo los signos del código agencial del destino del malevaje. Esto es decir que la fuerza que conduce al cambio total del signo paica arrabalera se complementa con el código del color que da la luz de la noche clara y estrellada. Por consiguiente, "Melodía de arrabal" se encuentra en consonancia con los textos tangos del corpus, en donde la significación de la noche cumple la función de iluminar a los habitantes del arrabal, porque la luna es amiga y cómplice como lo llega a ser el farol que dirige el sino de la niña-pebeta, quien espera coqueta al amparo de la luz de un farol a su hombre-macho que la hará mujer y quien, luego, la abandonará a su destino de paica del arrabal.

Sin embargo, aquí no se cierra la significación armónica del arrabal, dulce arrabal, lindo arrabal, arrabal mío, como se señala en los textos, sino que la melodía del arrabal es esencialmente armónica, porque entre paicas y compadritos, yiras y bacanes, minas y chorros la musicalidad del tango se energiza en el campo semántico del código del sonido tanto al ritmo armónico del canyengue como en el de la queja proyectado por el bandoneón. 


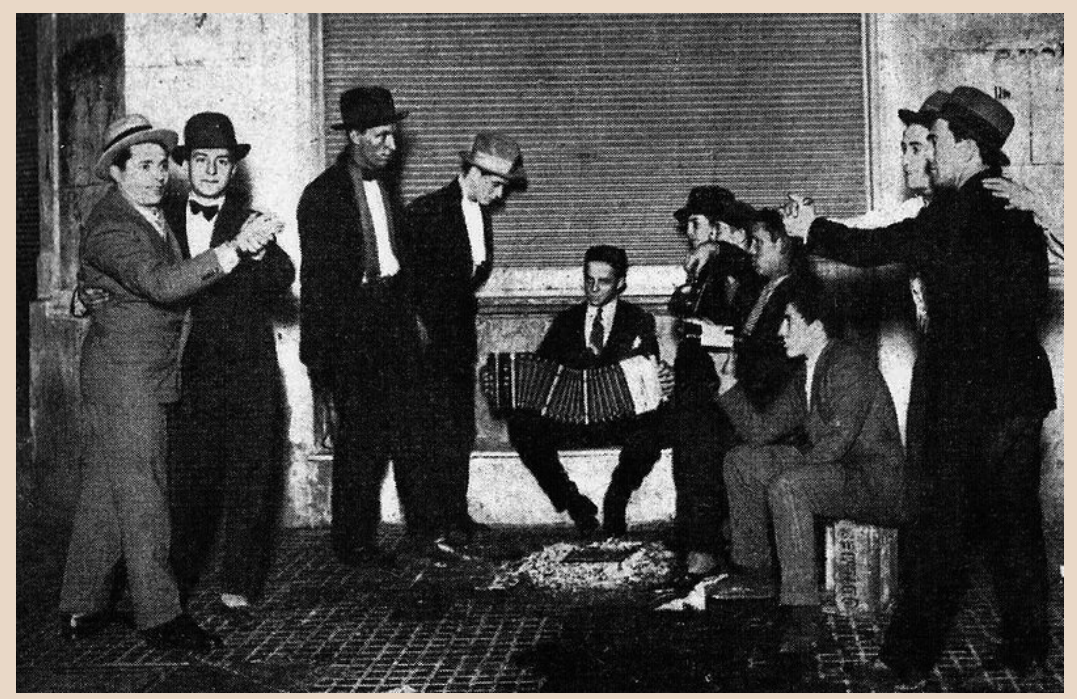

Tango entre hombres. Buenos Aires, c. 1910. Fuente: http://es.wikipedia.org/wiki/Tango

Cada personaje es agente y desempeña los roles que le asigna el destino del suburbio en el espacio fijado en las orillas del Río de la Plata. Entre los signos del barrial se reconocen: los ranchitos iguales del San Juan y el Pompeya a donde se entra por el callejón, se llega a la milonga o se irrumpe en el corralón para bailar, o bien, se ingresa al prostíbulo para ver a la mina si va dejando guita. Además, se realizan las continuas visitas a la bacana y, pasando por los estrechos caminos del conventillo en el keko arrabalero, se divisa a la yira entre callejones, así también, a una linda pebeta esperando ser desflorada por un macho, o bien, a la paica, quien ya por muy poca guita ha entregado su amor.

Si bien el tango es macho, el bacán se devuelve antes de ver la luz solar a su cotorro para dormir en su catrera y el chorro a su bulín. Estos signos liberan a estos agentes de la noche a quienes, además, depara el peligro cuando el día demanda la luz. En la medida que el sol está ausente del sino arrabalero, no es cómplice ni delata a quienes están fuera del código compartido por el malevaje; esto se infiere por la constante de la noche en las historias referidas. Así, el espacio configurado por la presencia del día es barrio; pues se debe a la actividad exterior desarrollada por los agentes nocturnos. No obstante, es en la noche cuando el malevaje está amparado por la luna y 
se canta la melodía del tango, mientras se queja el bandoneón; de manera que en la orilla se comparte y construye el reticulado del macrocódigo del arrabal: "mi lindo arrabal".

Cabe señalar que cada personaje del barrio asume un nuevo concepto bajo los signos del código del sonido, del espacio y del cromático. De esto se infiere que cada agente construye y se complementa según su estereotipo social para reconocerse como parte y vida del arrabal. Así, la connotación de los signos está compartida en otro funtivo del nuevo significado. Esto conduce a la interpretación de que los habitantes de la oscuridad como los bohemios subsisten en complicidad con la luz de la luna en la noche arrabalera; es decir que el rasgo positivo (+) obedece a que la luna se desplaza siguiendo el devenir de las historias de los agentes nocturnos. En este sentido más bien crítico, la luna alberga a los agentes del malevaje, tales como: ladrones, pebetas, paicas, compadres, chorros, minas, etc. para inyectarlos de vida $y$, por consiguiente, dejarlos en las condiciones apropiadas para cumplir su sino. Además, se dirá que todos estos códigos en conversación dialógica transitan en el espacio del barrio y se transforman en el suburbio como en el macrocódigo del arrabal. Al tiempo que estos signos registran el malevaje a través de la noche iluminada por la luna, la música generada por el quejido del bandoneón llena los espacios suburbanos de la orilla desde los exteriores hasta generar la complicidad: tanto en el cotorro o el conventillo como en el bullido keko. De forma que todos quienes viven al margen de la ley crean así el lenguaje de signos del lunfardo, el cual se valida entre los que sienten la melodía del arrabal y lo viven fieles a su destino de orilleros, deambulando en el total anonimato. Estos son: el ciruja, quien lo hará entre sórdidos arrabales y que, si bien libre y atorrante por cobrársela duro, subsiste por los recursos otorgados por una mina quien le da la guita que le saca al matón; o bien, de un Pato, del tango del mismo nombre, muchacho rante, atorrante y de barrio, falto de dinero y orillero (Gobello, 1996; Espíndola, 2002), quien por cosas del destino es ahora un bacán; sin embargo, "lo amenaza el destino" a raíz de que la "vida tiene más vueltas que una oreja" y, así, por su altivez al suburbio algún día volverá. Entonces, se dirá que éste como en otros textos se dibuja el estereotipo del bacán como un personaje milonguero y compadrón, señor del arrabal, pero vulnerable al destino entre las vueltas de la vida que lo puede convertir en un "ciruja" o, de lo contrario, terminar parado en una esquina "mangando" para el "buyón" (véase Gobello, 1996; Espíndola, 2002).

En relación a la interpretación dialógica entre los textos registrados, se dirá que estos revelan una estrecha consonancia entre los campos semán- 
ticos de cada código en donde no escapan los agentes predeterminados al suburbio y quienes comparten armónicamente al ritmo de la envolvente música del arrabal, amparados por la "noche clara" y con la "luna" cómplice de los que se sienten protegidos entre el malevaje. Esto último se justifica a través de que estos personajes conocen que en el espacio urbano (centro de la ciudad) no son bien recibidos y, por consiguiente, reaccionan despreciando a sus habitantes como a su estilo de vida. Se afirma esto, en la medida que las inferencias sobre el contenido de los textos recuperan ampliamente el valor de lo suburbano con variados epítetos que lo significan como el "hogar cálido" en expresiones tales como: viejo barrio, arrabal porteño, rinconcito arrabalero, barrio lindo, la emoción de mi suburbio, la ventanita de mi calle de arrabal, la luna de arrabal nos acompaña, pedazo de barrio, arrullo del suburbio, etc.

De los puntos desarrollados en el análisis se reconocen los signos que conforman los códigos semánticos. Fundamentalmente, con el propósito de hacer la lectura interpretativa del barrio, el espacio de la subcultura en la temática del tango canción contiene un discurso subyacente que conforma el arrabal. Es decir, los códigos explícitos del mismo espacio, agencial, cromático y del sonido, como la lectura del macrocódigo de la cultura del malevaje, en su conjunto activan el lenguaje del lunfardo, permitiendo la coherencia global del discurso subyacente: el arrabal.

En síntesis preliminar, se dirá que los aspectos relevantes de los niveles analizados se entrelazan en relación a la semiótica del arrabal, lo cual genera la lectura del signo estructurador del macrocampo semántico conectado y registrado con todos los signos de los códigos del arrabal.

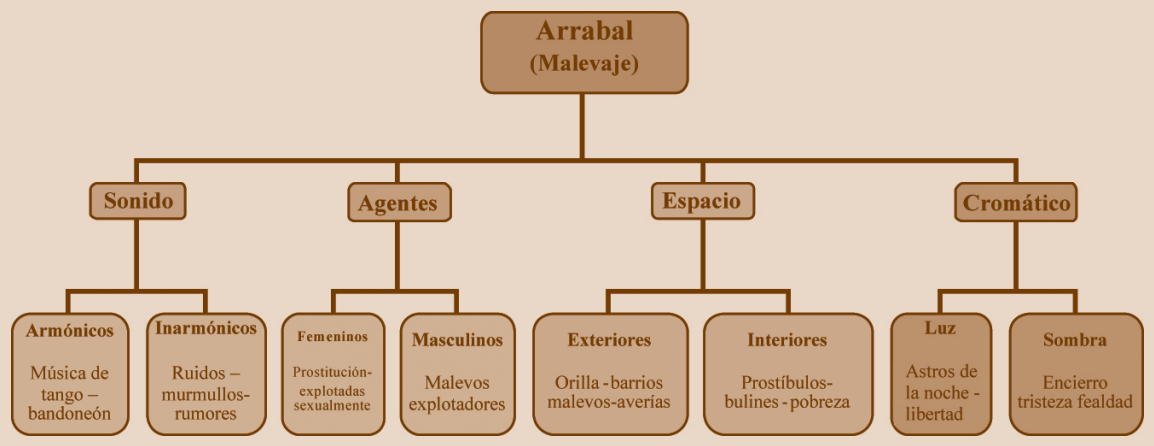

Figura 6. 


\section{CONCLUSIONES}

Este estudio interpretativo que toma como referente "Melodía de arrabal" (1932), abordó la lectura de los signos en los textos-canciones de tangos como discursos del arrabal, además, circunscrito para una época en donde los parámetros lingüísticos y sociales estaban vinculados al espacio de la subcultura y el suburbio bonaerense. Así, queda demostrado el fenómeno cultural del tango como el discurso que, si bien tuvo su apogeo a principios del siglo XX, mantiene aún vigencia cultural en el tiempo. Integrando lo anterior, se dirá que la lectura de estos signos se desarrolla sobre la base de los códigos generados por la cultura. En este caso, propiamente en el lenguaje o sociolecto del lunfardo, debidamente ilustrado en los campos semánticos de cada código (agencial, espacial, cromático y de sonido). Así mismo, a través de los elementos sígnicos que obedecen al análisis superficial hacia el subyacente, se descubre la coherencia textual y discursiva de los textos-canciones, la cual se potencia en la relación dialógica entre los signos para otorgar el valor a la lectura de los campos semánticos en una nueva significación. Esto último arroja como resultado que el análisis semiótico del barrio, espacio de la subcultura, se concreta como un discurso del arrabal.

Si bien la decodificación de los componentes de cada signo se debe a la interpretación, esta última guarda relación con la condición del interpretante; en la medida que los factores determinantes dependen de la experiencia pasada y el mundo cultural al cual pertenece cada individuo (Barthes et al., 1972; Eco, 1992, 1995). En este sentido, la interpretación de los textos canciones aludidos aquí es una muestra del estereotipo del mundo suburbano que exalta la acción conjunta del malevaje. En suma, el proceso de semiosis donde el signo implicado en el discurso tiene un valor cultural por la correlación entre los elementos del sistema, cobra validez sólo para el interpretante en la medida que el significado es leído como unidad cultural y el signo final, es decir el arrabal, se transforma en un nuevo campo semántico conectado a los signos entre sí. Esto último se sostiene por cuanto la lectura de las marcas semánticas conduce a la superrelevación de las connotaciones reguladas por los códigos y la cultura.

Finalmente, cabe señalar que la interpretación semiótica del modo humano de significar revela un mecanismo por el cual se hace la historia y la cultura. Esto es decir, es el modo como se define el mundo, permitiendo al hombre actuar sobre él y, por consiguiente, transformarlo. 


\section{REFERENCIAS}

Arteche, M. (1985). Tango que me hiciste bien. Santiago: Andrés Bello.

Barthes, R.; Bremond C.; Todorov T. y Metz C. (1970). La semiología (Colección Comunicaciones). Buenos Aires: Editorial Tiempo Contemporáneo.

Benveniste, E. (1997). "El aparato formal de la enunciación” (1970). En: Problemas de lingüística general II (pp. 82-91). D.F. México: Siglo XXI editores.

Eco, U. (1992). Los límites de la interpretación. Barcelona: Lumen. (1995). Tratado de semiótica general. Barcelona: Lumen.

Espíndola, A. (2002). Diccionario del lunfardo. Buenos Aires: Planeta.

Gobello, J. (1996). Tangos, letras y letristas. Buenos Aires: Plus Ultra. (1997). Letras de tangos. Selección (1897-1981). Tomo I, II. Bs. Aires:

\section{Centro Editor.}

(1997). Letras de tangos. Selección. Biografías de mujeres y hombres que hicieron el tango. Tomo III. Buenos Aires: Centro Editor.

Hozven, R. (1979). El estructuralismo literario francés. Santiago: Ediciones del Departamento de Estudios Humanísticos.

López, C. (1998). “Consideraciones sobre el machismo y el tango”. En: Tiempo de Tango $\mathrm{N}^{\circ}$ 5, enero-marzo. Cali: Univalle, pp. 15-17.

Menegazzo, L. (1974). Didáctica de la imagen. Comunicación visual y medios audiovisuales. España: Editorial Latina S.A.

Morris, Ch. (1985). Fundamentos de la teoría de los signos. Barcelona: Paidós.

Poblete, H. (1985). “Breve historia del tango". En: Tango que me hiciste bien (pp. 11-18). Santiago: Andrés Bello.

Reyes, G. (1997). El abecé de la pragmática. Madrid: Arco Libros.

Roa, A. (1989). Gramática castellana. Santiago: Salesiana.

Sábato, E. (1985). "Bandoneón y metafísica”. En: Tango que me hiciste bien (pp. 65-68). Santiago: Andrés Bello.

Salamanca, G. (2010). “Apuntes sociolingüísticos sobre la presencia de argentinismos en el léxico del español de Chile”. Atenea 502, 125-149.

Saussure, F. de ([1916] 1986). Curso de lingüística general. Buenos Aires: Losada.

Serna, J. M. (1979). “Origen sociolingüístico del tango”. En: Comunicación Social U.P.B. (pp. 1-8). Caldas: Universidad de Caldas.

Valdivieso, H. (1983). "Prestigio y estigmatización: factor determinante en la enseñanza institucionalizada de la lengua materna". RLA. Revista de Lingüística Teórica y Aplicada 21, 137-142. 


\section{ANEXO 1}

"Melodía de arrabal" (1932). Autores: Le Pera y Battistella. Cantada por Carlos Gardel en el filme del mismo nombre en 1932.

Barrio plateado por la luna, Rumores de milonga

Es toda tu fortuna;

Hay un fuelle que rezonga

En la cortada mistonga,

Mientras que una pebeta,

Linda como una flor,

Espera, coqueta,

Bajo la quieta luz de un farol.

Barrio, barrio,

Que tenés el alma inquieta

De un gorrión sentimental.

Pena, ruego,

Es todo el barrio malevo

Melodía de arrabal.

Viejo barrio,

Perdoná si al evocarte

Se me espianta un lagrimón,

Que al rodar en tu empedrao

Es un beso prolongao

Que te da mi corazón.

Cuna de taitas y cantares,

De broncas y entreveros

De todos mis amores.

En tus muros, con mi acero,

Yo grabé nombres que quiero:

Rosa, la milonguita;

Era rubia Margot;

Y en la primera cita

La paica Rita me dio su amor. 
ANEXO 2

\section{Textos-canciones del corpus}

“Melodía de arrabal". 1932. Letra de Alfredo Le Pera y M. Battistella y música de Carlos Gardel.

"El choclo". 1946. Letra de Enrique Santos Discépolo y música de Ángel G. Villoldo.

"Barrio Reo". 1927. Letra de Alfredo Navarrine y música de Roberto Fugazot.

"Pobre paica". 1914. Letra de Pascual Contursi y música de Juan Carlos Cobián

“Arrabalero". 1927. Letra de Eduardo Calvo, música de Osvaldo Fresedo.

"Arrabal amargo". 1935. Letra de Alfredo Le Pera y música de Carlos Gardel.

"Luna de arrabal". 1934. Letra de Enrique Cadícamo y música de J. L. Sanders.

“Tango". 1942. Letra de Homero Manzi y música de Sebastián Piana.

"Mi Buenos Aires querido". 1934. Letra de Alfredo Le Pera y música de Carlos Gardel.

"Sur". 1948. Letra de Homero Manzi y música de Aníbal Troilo.

"Barrio de tango". 1942. Letra de Homero Manzi y música de Aníbal Troilo.

"La última curda". 1956. Letra de Cátulo Castillo y música de Aníbal Troilo.

“Tinta roja”. 1941. Letra de Cátulo Castillo y música de Sebastián Piana.

"El bulín de la calle Ayacucho". 1923. Letra de Caledonio Flores y música de José y Luis Servidio.

"Malena". 1942. Letra de Homero Manzi y música de Lucio Demare.

"Motivo". 1914. Letra de Pascual Contursi y música de J. C. Cobián.

"Ladrillo". 1926. Letra de Juan Andrés Caruso y música de Juan de Dios Filiberto.

“Canción de Buenos Aires". 1932. Letra de M. Romero y Azucena Maizani. Música de O. Cúfaro.

"Margot". 1921. Letra de José Rosario y Caledonio Flores y música de Carlos Gardel.

"Palermo". 1929. Letra de Juan Villalba y Hermido Braga. Música de Enrique Delfino.

"Mocosita". 1926. Letra de Víctor Soliño y música de Gerardo Matos Rodríguez.

“Un tropezón”. 1927. Letra de Luis Bayón Herrera y música de Raúl de los Hoyos.

“Madreselva”.1930. Letra de Luis César Amadori y música de Francisco Canaro.

"Viejo rincón". 1925. Letra de Roberto Cayol y música de Raúl de los Hoyos.

"Cambalache". 1935. Letra y Música de Enrique Santos Discépolo. 
"La que murió en París". 1930. Letra de Héctor Pedro Biomberg y música de Enrique Maciel.

"Madame Ivonne". 1933. Letra de Enrique Cadícamo y música de E. Pereyra.

"Pato". 1928. Letra y Música de Ramón Collazo.

"Dandy". 1928. Letra de A. Irusta y música de Lucio Demare.

"Garufa”. 1928. Letra de Roberto Fontaina y V. Soliño, música de Juan A. Collazo.

“Apología del tango". 1929. Letra y música de Enrique Pedro Maroni.

"El ciruja". 1926. Letra de Francisco Alfredo Marino y música de Ernesto de la Cruz. 